\title{
O trabalho dos cuidadores de idosos na perspectiva da economia do care
}

\section{Priscila Cerutti ${ }^{1}$}

https://orcid.org/0000-0003-1885-9668

Jandir Pauli ${ }^{2}$

https://orcid.org/0000-0003-4618-6958

\author{
Vanessa $\operatorname{Rissi}^{3}$ \\ http://orcid.org/0000-0002-1895-9354 \\ Paula Gomes ${ }^{2}$ \\ https://orcid.org/0000-0002-8803-4947
}

\author{
${ }^{1}$ Faculdade Anhanguera, Passo Fundo, RS, Brasil \\ ${ }^{2}$ Faculdade Meridional, Escola de Administração, Programa de Pós-Graduação Stricto Sensu em Administração, Passo Fundo, RS, Brasil \\ ${ }^{3}$ Faculdade Meridional, Escola de Psicologia, Programa de Pós-Graduação Stricto Sensu em Psicologia, Passo Fundo, RS, Brasil
}

\section{O trabalho dos cuidadores de idosos na perspectiva da economia do care}

Resumo: As características e os desafios do trabalho dos cuidadores de idosos ainda são pouco investigados no Brasil. O presente artigo tem por objetivo explorar as percepções de cuidadores de idosos sobre seu trabalho a partir da perspectiva da Economia do Care. Por meio de uma pesquisa qualitativa, foram realizadas dez entrevistas com cuidadores que atendem no próprio domicílio do idoso. As entrevistas foram realizadas com base em um roteiro semiestruturado e analisadas por meio da técnica de análise de conteúdo. Dessa análise emergiram quatro categorias sobre as características e desafios desse trabalho: a) apresenta-se aos cuidadores como necessidade para complementar a renda; b) é fonte geradora de sofrimento físico e psíquico; c) os cuidadores criticam a mercantilização do cuidado; e, d) apontam dificuldades para ajustar relações de intimidade, envolvimento afetivo e remuneração do trabalho. Os resultados permitem explorar as subjetividades envolvidas nesse trabalho e apontar intervenções para sua qualificação, oferecendo melhores condições aos cuidadores no ato de cuidar.

Palavras-chave: Economia do care. Intimidade. Cuidadores. Idoso.

\section{The work of elderly caregivers from the perspective of the care economy}

Abstract: The characteristics and work challenges of elderly caregivers are still little studied in Brazil. This article aims to explore the perceptions of elderly caregivers about their work from the perspective of the care economy. Through qualitative research, ten interviews were conducted with caregivers who offer their services to the elderly population in the person's home. The interviews were conducted based on a semi-structured script and analyzed through content analysis. The study proposes four categories related to characteristics and challenges of this work: a) the job is presented to caregivers as a need to complement income; b) the job is a source of physical and mental suffering; c) caregivers criticize the commodification of care; and d) it points out difficulties in adjusting relationships of intimacy, affective involvement, and work compensation. The results allow exploring the subjectivity of this work and point out interventions to train workers, offering better conditions to caregivers.

Keywords: Care economy. Intimacy. Caregivers. Elderly.

Recebido em 18.09.2018. Aprovado em 20.11.2018. Revisado em 29.04.2019.

CC O(s) Autor(es). 2019 Acesso Aberto Esta obra está licenciada sob os termos da Licença Creative Commons Atribuição-NãoComercial 4.0 Internacional (https://creativecommons.org/licenses/by-nc/4.0/deed.pt_BR), que permite copiar, distribuir e reproduzir em qualquer meio, bem como adaptar, transformar e criar a partir deste material, desde que para fins não comerciais e que você forneça o devido crédito aos autores e a fonte, insira um link para a Licença Creative Commons e indique se mudanças foram feitas. 


\section{Introdução}

Envelhecer causa grandes transformações fisiológicas e psicológicas, leva as pessoas idosas a alterações em seus hábitos e procedimentos, de forma que não consigam, muitas vezes, realizar as atividades com autonomia, necessitando que um cuidador as acompanhe e as auxilie diariamente. Assim, demanda-se por novos profissionais e produção de conhecimento em torno da temática do envelhecimento, surgindo o mercado de cuidadores de idosos (PAULI; GOERGEN; GOLDONI, 2017).

Foi com a Política Nacional de Saúde do Idoso, em 1999, que se estabeleceu a definição de cuidador, entendido como uma pessoa que realiza cuidados voltados às pessoas idosas, que se encontram doentes ou dependentes na realização de suas atividades diárias (BRASIL, 1999). Esse mercado exige profissionais com conhecimentos e habilidades para intervir de maneira adequada, de acordo com as necessidades de cada idoso (GUIMARÃES, 2016; HARTKE; KING; HEINEMANN; SEMIK, 2006). O Projeto de Lei do Senado nº 284, de 2011 (BRASIL, 2011), que trata de regulamentar a profissão de cuidador de idosos no Brasil, foi aprovado na respectiva Casa Legislativa em 2012, sendo encaminhado no mesmo ano à Câmara dos Deputados, onde desde então aguarda aprovação para se tornar lei (BRASIL, 2012).

As tarefas realizadas pelo cuidador podem vir a gerar eventos estressores significativos, causando sofrimento e prejuízos ao profissional (CARRARO; MAGALHÃES; CARVALHO, 2016). Isso especialmente quando os profissionais buscam o trabalho de cuidador como algo informal, como uma segunda profissão (LOPES; MITRE; COELHO; QUEIROZ, 2012). Somam-se, ainda, as duplas jornadas de trabalho, aliadas à repetição de tarefas, à falta de garantias e direitos, e, ao baixo salário da profissão (MARTINEZ; BRÊTAS, 2004).

Além desses componentes estressores típicos da organização do trabalho, este estudo considera que há um aspecto elementar relacionado à natureza do trabalho e que interfere na saúde do cuidador: o componente afetivo inerente às relações de cuidado. Essa perspectiva, conhecida como economia do cuidado (Care Economy), sugere que o trabalho do cuidador possui características próprias e tem-se mostrado um grande desafio na contemporaneidade (THE CARE..., c2018). Nesse plano, este estudo pretende discutir a relação de intimidade criada no cuidado, recuperando um debate que sociólogos do trabalho e economistas têm evitado (BANDELJ; MORGAN; SOWERS, 2015).

Os estudos de Zelizer (2005) fornecem uma concepção clara do vínculo entre intimidade e economia. Para a autora, intimidade refere-se ao estado de ser pessoalmente íntimo, ter amizade ou disponibilizar de conhecimento, intercâmbio familiar ou familiaridade próxima (ZELIZER, 2005). E, por isso, as pesquisas sobre a relação entre os aspectos íntimos e econômicos estudam como a intimidade influencia as atividades econômicas, englobando objetos íntimos, como corpos e olhares, considerando interpretações do seu potencial intercâmbio econômico (ZELIZER, 2005).

Nessa perspectiva, este estudo pretende trazer uma contribuição acerca dos reflexos que o trabalho do cuidador de idosos traz ao profissional que desempenha essa atividade. Por isso, buscou explorar percepções de cuidadores de idosos sobre a profissão, a partir da perspectiva da economia do care, em dez cuidadores que exercem a profissão no domicílio do idoso. Acredita-se que compreender o trabalho dos cuidadores de idosos pode trazer luzes para mostrar como as relações de trabalho estão permeadas por relações de afetividade, especialmente se for considerada a natureza desse mercado.

\section{O mercado dos cuidados aos idosos e a subjetividade do trabalhador}

Cuidadores de idosos trocam seus serviços por um salário, transformando suas disposições afetivas e morais em uma mercadoria. Essa mercabilidade da afetividade é compreendida por um marco de processos precários das relações familiares e por uma ruptura na dinâmica das reciprocidades familiares, em que filhos e netos não cuidarão dos seus pais e avós (BATISTA; ARAÚJO, 2011). Somando-se a isso, as alterações efetuadas no âmbito familiar demonstram que o trato com idosos em domicílio tornou-se uma tarefa difícil, fazendo com que a socialização familiar adquira aspecto de mercadoria, em que valores econômicos misturamse ao espaço do íntimo (BATISTA; ARAÚJO, 2011; SAIDEL; CAMPOS, 2017).

Essa ruptura na dinâmica familiar baseou-se no pressuposto de que pessoas mais velhas preferiam viver de forma independente. $\mathrm{O}$ cuidado foi categorizado em vários domínios e cada um exigindo suas próprias habilidades especiais: cuidados físicos, assistência diária e assistência médica. Em outras palavras, o cuidado tornou-se mensurável, específico e atribuído a grupos específicos de pessoas profissionalizadas (DA ROIT; DE KLERK, 2014). Desse modo, o cuidado veio a ser enquadrado como uma mercadoria que poderia ser comprada pelos consumidores (MOL, 2008). 
Além do cuidado físico, existem questões emocionais, como a história de vida, dor do abandono, sentimentos e emoções que vêm à tona no momento do cuidado, fazendo com que o cuidador saiba lidar individualmente com a necessidade física e emocional de cada idoso (FIGUEIREDO, 2009). Esse cuidado, especial e individual, é necessário, pois o avanço da idade causa um enfraquecimento e diminuição gradual na capacidade funcional, ocasionando déficits permanentes de função física e eficiência psicomotora (BARCA; ENGEDAL; LAKS; SELBÆK, 2011).

Outro fato presente na atividade de cuidador de idosos envolve a culpabilidade despertada na relação subjetiva do cuidador (SZNELWAR; UCHIDA; LANCMAN, 2011). Toma-se o exemplo de cuidadores de uma instituição de longa permanência de idosos na França, onde os profíssionais relatam não terem sido suficientemente vigilantes ao não perceberem a fuga de um idoso com mal de Alzheimer, nunca mais encontrado. Ou até mesmo no Japão, onde um idoso cometeu suicídio ao se jogar do segundo andar da casa de longa permanência (BORGEAUD-GARCIANDÍA, 2016). A pesquisa mostra que a culpabilidade se mostra presente nesses cuidadores, que se sentem responsáveis pelos acontecimentos negativos com os idosos e não terem como reverter a situação (BORGEAUD-GARCIANDÍA, 2016).

Ao realizar uma atividade que envolve o cuidado com

\section{[...] compreender o trabalho}

dos cuidadores de idosos

pode trazer luzes para

\section{mostrar como as relações de}

trabalho estão permeadas por

relações de afetividade [...] outra pessoa, torna-se difícil cumprir procedimentos sem olhar com o engajamento da subjetividade (SZNELWAR; UCHIDA; LANCMAN, 2011). O trabalho transforma o indivíduo (LIMA, 2012), e no caso do cuidador de idosos as atividades implicam a esfera emocional, o afeto, a inteligência e subjetividade do profissional, ultrapassando as barreiras prescritas. Por outro lado, os cuidadores de idosos, muitas vezes, buscam essa atividade como uma segunda profissão, realizando jornada dupla de trabalho (LOPES; MITRE; COELHO; QUEIROZ, 2012; MARTINEZ; BRÊTAS, 2004). Esse duplo vínculo, somado à repetição das tarefas, à sobrecarga, aos baixos salários, pode vir a gerar sofrimentos, tanto físicos quanto emocionais nos cuidadores, resultando muitas vezes em solicitações de licenças médicas

\section{(MARTINEZ; BRÊTAS, 2004; SILVA; MACHADO; FERREIRA; RODRIGUES, 2015).}

O foco principal para análise do trabalho do cuidador está no potencial que cada cuidador tem para utilizar seus próprios recursos, internos ou externos, na transformação do sofrimento no exercício da profissão em prazer e realização (FALEIROS; SANTOS; MARTINS; HOLANDA; SOUZA; ARAÚJO, 2015). No caso dos cuidadores de idosos, isso não é diferente, pois a rotina em determinados momentos é gratificante pela sensação de bem-estar, no entanto, outros momentos mostram-se desgastantes, cansativos, estressores, acarretando o sofrimento físico e emocional (ROTE; ANGEL; MARKIDES, 2015).

\section{Cuidado, intimidade e economia}

Profissionais que se debruçam com as condições da mercabilidade do cuidado, deparam-se com os investimentos emocionais que perpetuam a relação social de trabalho tecidos na intimidade (GUIMARÃES, 2016; ZELIZER, 2005). É fundamental a existência de relações interpessoais quando se trata da vida em sociedade, uma vez que, nas atividades profissionais também existirá a pessoalidade e as trocas, seja em termos simbólicos, práticos e afetivos, entre os sujeitos envolvidos (ZELIZER, 2010).

Isso não é diferente na profissão dos cuidadores de idosos, que exige, muitas vezes, um nível elevado de trocas afetivas e íntimas entre o cuidador e o paciente, para que o cuidado seja realizado de uma maneira eficaz. Nesse sentido, a intimidade refere-se a relações que "[...] dependem em conhecimento particularizado recebido e atenção prestada por, pelo menos, uma pessoa, com conhecimento e atenção que não estão amplamente disponíveis para terceiros". (ZELIZER, 2005, p. 14, tradução nossa).

Essa troca de intimidade vai depender do grau de confiança criado dia após dia entre cuidador e idoso (PIRES; MAZON, 2017; ZELIZER, 2010). Exige-se compreensão mútua e confiança entre os atores envolvidos, sendo um dos aspectos mais importantes para que se mantenha em um nível satisfatório a relação, não apenas para o paciente, mas também para o cuidador responsável (SCHORCH; WAN; RANDALL; WULF, 2016). Muitas vezes, os idosos preferem compartilhar dessa intimidade com o cuidador, pois os cuidadores já conhecem e compreendem suas necessidades e anseios, devido ao longo período de convivência. 
No estudo de Pires e Mazon (2017) foram avaliadas 25 técnicas de enfermagem que possuíam pelo menos um (1) ano de experiência como cuidadoras de idosos. A pesquisa revelou que a intimidade entre o cuidador e o paciente inicia desde a administração de medicamentos, nas questões alimentares, atividades como corte de cabelo, escovar os dentes, banho, escolher a roupa que o idoso irá usar, o acompanhamento nas consultas médicas, que ocasionam uma participação íntima dos processos vivenciais diários do paciente.

Contudo, o cuidado vai além dessas questões. O cuidador necessita tocar o corpo da pessoa cuidada, seja nos momentos de higiene ou até de trocas de curativos, precisa trocar as fraldas, entrando em contato visual com a urina e fezes, caracterizado, muitas vezes, como um trabalho sujo (TWIGG, 2000). Exige do profissional tato, discrição, empatia e compaixão, aspectos que juntos traduzem em estratégias empregadas nas interações que esse trabalho exige, é um saber fazer íntimo, saber complexo incorporado, que se adquire ao mesmo tempo em que se revela, na prática que traz sentido (BATISTA; ARAÚJO, 2011).

Ainda, incluem-se elementos como segredos compartilhados, informações corporais, memórias de situações difíceis e rituais pessoais (PIRES; MAZON, 2017) que indicam condições de afeto e suporte emocional (ZELIZER, 2010). Isso acarreta, muitas vezes, que o trabalho desenvolvido vai além de ser cuidador. Justificase eticamente o envolvimento emocional existente entre o cuidador e o idoso quando há estabelecimento de laços profundos, e comparações podem vir à tona, trazendo vivências como pais e fillhos ou daqueles que já partiram. Esse envolvimento pode gerar, quando da perda de um idoso, por ocasião de falecimento, profundas dificuldades emocionais e tristezas ao cuidador (PIRES; MAZON, 2017).

A partir dessa relação entre a intimidade e a economia, surge o conceito de Economia do Care (ZELIZER, 2010) com a ideia de um duplo sentido, em que paga-se pela intimidade ao realizar a contratação de um cuidador, ao mesmo tempo em que o domínio dessa intimidade interfere a forma de organização das pessoas envolvidas (ZELIZER, 2010). A dualidade, ou dicotomização entre economia e intimidade é conhecida como teoria das esferas separadas (ZELIZER, 2005), e está apoiada na visão clássica de que cada uma dessas esferas opera de acordo com princípios individuais, tais como: sentimentos, impulsos e solidariedade de um lado, e de outro, racionalidade, planejamento e eficiência (ZELIZER, 2005).

\section{Procedimentos Metodológicos}

A escolha da metodologia qualitativa para discutir o trabalho dos cuidadores de idosos seguiu alguns pressupostos básicos: a) por permitir uma investigação cujo desenho de pesquisa está em constante evolução, permitindo a descoberta de relações entre fenômenos e o surgimento de novos pressupostos teóricos para análise da realidade; b) por ser apropriada quando a estratégia de pesquisa propõe uma aproximação com um novo fenômeno, permitindo a descoberta de evidências; c) por permitir sínteses narrativas de fenômenos complexos; d) por auferir significado a contextos social e culturalmente específicos; e, e) por permitir ao pesquisador-observador ser o agente do processo de pesquisa (DENZIN; LINCOLN, 2005).

Deste modo, foi realizada uma entrevista semiestruturada, com um roteiro de questões baseadas no referencial teórico exposto anteriormente. As perguntas foram divididas em três blocos: a) organização do trabalho; b) sofrimento e intimidade; e, c) caracterização do perfil dos entrevistados. Quanto à escolha dos participantes, a seleção de cuidadores para entrevista se deu por conveniência, a partir da definição de um perfil que contribuísse para o entendimento do problema de pesquisa proposto. O pesquisador seleciona intencionalmente os participantes e os locais que melhor o ajudarão a entender o problema ou a questão de pesquisa (CRESWELL, 2007).

Para tanto, foram entrevistados dez cuidadores de idosos que possuem outros empregos formais como principal profissão e exercem a atividade de cuidador de idosos como um trabalho complementar. Os entrevistados desenvolvem as atividades de cuidador no turno inverso de suas outras profissões, nos finais de semana ou de acordo com uma demanda específica. Foram escolhidos intencionalmente por acessibilidade e caracterizados nesse estudo com a letra $\mathrm{C}\left(\mathrm{C}_{1}, \mathrm{C}_{2} \ldots \mathrm{C}_{10}\right)$ (Tabela 1). Buscou-se por profissionais que estivessem na profissão há mais de dois anos com o objetivo de agregar maior contribuição com a pesquisa, independente de escolaridade, nível socioeconômico, idade ou sexo. Todos os entrevistados estavam cientes que a entrevista aconteceria no dia e horário marcado que pudesse não atrapalhar a rotina. Somente após o retorno com o agendamento confirmado um dos pesquisadores deslocavase em local combinado para a realização das entrevistas. 
Tabela 1 - Características dos profissionais cuidadores de idosos entrevistados neste estudo

\begin{tabular}{ccccll}
\hline Cuidador & Sexo & Idade (anos) & Anos de profissão & Escolaridade & Profissão principal \\
\hline $\mathrm{C}_{1}$ & Fem. & 32 & 5 & Ensino técnico & Téc. Enfermagem \\
$\mathrm{C}_{2}$ & Masc. & 48 & 20 & Ensino técnico & Téc. Enfermagem \\
$\mathrm{C}_{3}$ & Fem. & 30 & 3 & Ensino médio & Artesã \\
$\mathrm{C}_{4}$ & Fem. & 65 & 32 & Ensino médio & Téc. Enfermagem \\
$\mathrm{C}_{5}$ & Fem. & 48 & 8 & Ensino médio & Téc. Enfermagem \\
$\mathrm{C}_{6}$ & Fem. & 51 & 10 & Ensino técnico & Téc. Enfermagem \\
$\mathrm{C}_{7}$ & Fem. & 46 & 10 & Ensino médio & Garçonete \\
$\mathrm{C}_{8}$ & Fem. & 45 & 15 & Ensino superior & Enfermeira \\
$\mathrm{C}_{9}$ & Masc. & 39 & 13 & Ensino superior & Enfermagem \\
$\mathrm{C}_{10}$ & Fem. & 37 & 2,5 & Ensino médio & Caixa de loja \\
\hline
\end{tabular}

Fonte: Elaboração própria.

As entrevistas foram realizadas no mês de janeiro de 2018 em uma cidade no Sul do Brasil. Solicitou-se a colaboração voluntária dos profissionais cuidadores no sentido de contribuírem com o estudo, respondendo algumas perguntas. Estando cientes das condições de participação na pesquisa, foi-lhes apresentado o Termo de Consentimento Livre e Esclarecido (TCLE), informando que não havia resposta certa ou errada, e que seria assegurado o anonimato das respostas, e que estas seriam tratadas em seu conjunto, para fins científicos. Após $\mathrm{o}$ aceite e preenchimento do TCLE a entrevista era iniciada. As entrevistas foram realizadas individualmente, em ambiente agradável, sem interrupções externas. As falas foram gravadas com gravador de áudio, com duração aproximada de uma hora cada e posteriormente transcritas. Nenhum dos pesquisadores possui vínculo com os entrevistados (nem seus familiares).

No que se refere à averiguação dos resultados, utilizou-se a técnica de análise de conteúdo (BARDIN, 2009) em que se desenvolvem três etapas: pré-análise, exploração do material e tratamento dos dados e interpretação. Após a criação das categorias iniciais o material foi reduzido, de tal forma que restassem apenas os conteúdos mais relevantes pautados às categorias. O processo de categorização resultou em 22 códigos que contemplavam as categorias iniciais, oriundas do roteiro de entrevistas, gerando 133 sistemas de códigos. A partir da categorização maior, realizou-se a análise com mais profundidade, na busca de detalhes e informações relevantes trazidas nas entrevistas, que resultou na estruturação das categorias finais do estudo (Quadro 1).

\section{Quadro 1 - Categorias finais e ideias principais das categorias}

\begin{tabular}{|c|c|c|}
\hline Categorias finais & Ideias principais & Falas dos entrevistados \\
\hline Por que ser cuidador? & $\begin{array}{l}\text { - Fonte de renda; } \\
\text { - Gostar da profissão; } \\
\text { - Trabalho extra. }\end{array}$ & $\begin{array}{l}\text { "Faço este trabalho de cuidadora para ajudar na renda, dá um dinhei- } \\
\text { rinho bem bom, sempre ajuda". (C7, } 46 \text { anos). } \\
\text { "Gosto muito da minha profissão, trabalho na área da saúde faz } 13 \\
\text { anos e me sinto muito bem nessa área". (C9, } 39 \text { anos). }\end{array}$ \\
\hline $\begin{array}{l}\text { Percepções de sofri- } \\
\text { mento na profissão }\end{array}$ & $\begin{array}{l}\text { - Expectativa X realidade; } \\
\text { - Sofrimento físico e psíquico; } \\
\text { - Sobrecarga de trabalho; } \\
\text { - Falta de reconhecimento. }\end{array}$ & $\begin{array}{l}\text { "Quando começa, acha que é uma coisa, e depois é bem diferente é } \\
\text { bem trabalhoso". (C4, } 65 \text { anos). } \\
\text { "Não somos reconhecidos como deveríamos". (C1, } 32 \text { anos). }\end{array}$ \\
\hline $\begin{array}{l}\text { Mercantilização do cui- } \\
\text { dado }\end{array}$ & $\begin{array}{l}\text { - Abandono familiar; } \\
\text { - Dinheiro como solucionador; } \\
\text { - Esperança de voltar para casa; } \\
\text { - Livrar-se de um peso na família. }\end{array}$ & $\begin{array}{l}\text { "Tem de tudo, o que mais tem éo abandono, eles acham que o dinheiro } \\
\text { pode suprir isso". (C8, } 45 \text { anos). } \\
\text { "Eu acho, bem na verdade, que eles se tornam um fardo para a fami- } \\
\text { lia, porque eles são dependentes em quase tudo". (C6, } 51 \text { anos). }\end{array}$ \\
\hline
\end{tabular}




\begin{tabular}{|c|c|c|}
\hline $\begin{array}{l}\text { Envolvimento afetivo e } \\
\text { íntimo com o idoso }\end{array}$ & $\begin{array}{l}\text { - Desenvolvimento do luto; } \\
\text { - Compartilhamento de segredos e pre- } \\
\text { sentes; } \\
\text { - Cuidadores como parte da família; } \\
\text { - Confiança e carência dos idosos. }\end{array}$ & $\begin{array}{l}\text { "E segredos existe sim, muitos. Você acaba criando um vínculo de } \\
\text { cumplicidade, de confiança". (C3, } 30 \text { anos). } \\
\text { "Tem uns que tratam a gente igual os da família, tratam bem a } \\
\text { gente". (C5, } 48 \text { anos). }\end{array}$ \\
\hline
\end{tabular}

Fonte: Elaboração própria.

A seguir serão expostas a análise e interpretações das entrevistas de acordo com a literatura proposta.

\section{Análise e discussão dos resultados}

A primeira categoria listada descreve a percepção dos cuidadores acerca da profissão, no sentido de entender o que leva esses profissionais a desenvolverem a atividade de cuidador. Os entrevistados mencionam que a renda que recebem em seu emprego principal formal é insuficiente, necessitando de um complemento, conforme identificado: "bom, eu busquei trabalhar com idosos para complementar minha renda, porque o que a gente ganha é pouco e não da". (C2, 32 anos). Ainda, outra cuidadora comenta que: "minha família diz que eu trabalho demais, mas eu sei que isso é temporário, agora tem que ser assim, eu preciso trabalhar, preciso do dinheiro". (C5, 48 anos).

Além da necessidade financeira, alguns cuidadores, em número minoritário, relatam que exercem essa profissão por gostar daquilo que fazem, realizando sempre com dedicação e amor as atividades que lhes competem. Essa profissão traz vivências positivas e satisfação aos cuidadores, representando para alguns uma missão de vida que eles devem cumprir, pois: "eu nunca pensei em desistir não, até eu ter saúde vou trabalhar e cuidar deles. Acho que a gente tem uma missão na vida e a minha é isso, cuidar das pessoas". (C5, 48 anos). Isso está ligado à avaliação cognitiva e afetiva que o cuidador faz da própria vida, experimentando em atividades que lhes dão prazer e satisfação (FALEIROS; SANTOS; MARTINS; HOLANDA; SOUZA; ARAÚJO, 2015).

Na segunda categoria encontrada, observam-se questões relacionadas ao sofrimento que a profissão de cuidador de idosos causa nos profissionais. O sofrimento causado pelo trabalho torna-se evidente quando as questões que anteriormente eram prazerosas, não são mais vistas como satisfatórias, é quando a parte criativa do trabalho cessa (SZNELWAR; UCHIDA; LANCMAN, 2011). Esse sofrimento gerado no trabalho contempla aspectos que criam, muitas vezes, uma sobrecarga na função, onde o cuidador deixa de cuidar de si, para dedicar total atenção ao outro (ROCHA; VIEIRA; SENA, 2008; ROTE; ANGEL; MARKIDES, 2015), conforme o exemplo relatado?

Logo que ela [idosa] começou a ficar doente eu já tinha outro serviço. Um dia ela me ligou para saber onde que estava um pacotinho que ela tinha guardado. Tu acredita que ela disse que era um pacotinho com dinheiro e insinuou que eu tinha pego? Dai depois a filha dela achou esse dito pacote, porque ela tinha trocado de lugar e não lembrava, foi quando iniciou a doença da idosa. Uns dias depois, foi um brinco, ela de novo queria que eu desse conta do brinco. Então foi aí que eu decidi sair, porque começou a ficar perigoso. Como eu ia provar que não tinha pego? [...] Nossa eu sofri muito na época, porque eu precisava do salário. (C7, 46 anos).

Além do sofrimento, a expectativa criada pelo cuidador antes de iniciar seu contrato de trabalho diferese da realidade, pois o cuidador recebe uma série de atividades a desenvolver, mas no ato de cuidar é submetido a fazer tarefas que não estavam prescritas. Isso se deve pelo fato que: "nunca você segue o que está especifico no contrato, geralmente quando se trata de cuidar é algo diferente, tu não fica só cumprindo o horário e indo embora, tu sabe que aquilo é teu trabalho, tu acaba se apegando". (C3, 30 anos).

A sobrecarga de trabalho que a profissão de cuidador exige é notada pela maioria dos entrevistados, que também pode ser um fator gerador do sofrimento entre os profissionais (MARTINEZ; BRÊTAS, 2004). Nesse contexto, a C8 (45 anos) diz que,

É agitado, não tem tempo de ficar parada. Eu tenho muitas horas, não sobra muito tempo para fazer outras coisas. Lá pela meia noite acalma, aí a gente tem um intervalo para lanchar e descansar, mas às vezes quando tem paciente muito doente, ou muito agitado, tem dias que não dá para parar. 
E ainda: "há sobrecarga de trabalho, tem banho, troca de fraldas, administração de medicamentos, passeio e a gente tem 15 minutos de intervalo". (C2, 48 anos). A C6 (51 anos) complementa: "a gente trabalha bastante, nossa, é bem corrido, às vezes não sobra tempo nem de ir ao banheiro". Esse acúmulo de tarefas juntamente com as diferenças criadas entre o trabalho prescrito e o trabalho que realmente é executado pelos cuidadores pode vir a gerar um comportamento de fuga, fazendo com que os profissionais venham a abandonar a profissão, conforme mencionado: "sim, eu tinha uma colega durante o curso que não aguentou muito, pegou e largou de mão, é sofrido. Eu acho que a pessoa tem que estar prepara$d a "$. (C10, 37 anos).

A falta de reconhecimento a que esses profissionais são submetidos, também ficou evidente, pois: "não somos reconhecidos como deveríamos. Fizemos das tripas coração e nunca é o suficiente, nunca está bom". (C1, 32 anos). O trabalho de cuidador é visto como um trabalho frequentemente instável, mal remunerado, com poucas possibilidades de formação e promoção na carreira, pois ainda não existem diretrizes curriculares nacionais que se referem à profissão de cuidador, dificultando assim, a divergência para um currículo unificado (MARTINEZ; BRÊTAS, 2004; SILVA; MACHADO; FERREIRA; RODRIGUES, 2015). Isso leva a refletir acerca de qualificação exigida a esses profissionais, dados que os cuidadores são escolhidos independentemente da sua experiência ou escolaridade.

A terceira categoria do estudo contempla aspectos relacionados à mercantilização do cuidado, em que, para a maioria dos cuidadores, o dinheiro é capaz de comprar tudo, inclusive o afeto e o carinho que os idosos necessitam. $\mathrm{O}$ abandono é comum, conforme falado:

[...] pagam e não precisam vim ver, saber como está, dar um abraço, essas coisas. A gente vê a diferença, os casos que têm o abandono e aqueles que recebem visitas, é muita diferença. Quem recebe a visita é mais feliz, ficam faceiros, os outros é uma tristeza só. Mas o dinheiro é isso, pagar para o outro resolver o teu problema, porque eu acho isso, que os que não se importam, esses estão pagando para você cuidar do problema deles. (C8, 45 anos).

E essa situação não significa somente uma ruptura na dinâmica de solidariedade e reciprocidade familiar. Por exemplo, filhos que não cuidarão de seus pais, mas também, uma feição de mercadoria nas disposições morais e afetivas construídas historicamente, que assumem valores econômicos no espaço íntimo daqueles que cuidam das pessoas idosas (BATISTA; ARAÚJO, 2011). Essas alterações representam uma tarefa difícil e uma sobrecarga na socialização familiar, em que o cuidado com idoso torna-se um aspecto de mercadoria (SAIDEL; CAMPOS, 2017) e o fornecimento de cuidados para pais ou membro da família podem criar um ambiente propício ao estresse, na medida em que exige tempo substancial, recursos e trabalho de emoção (ROTE; ANGEL; MARKIDES, 2015).

Apesar desse abandono afetivo há aqueles que são jogados em uma clínica ou até mesmo no hospital e nunca mais procurados por seus familiares. Aquela visita que estava marcada, aquele abraço do ente querido ficam eternamente à espera e o cuidador torna-se a única pessoa que o idoso possui. Outros aguardam ansiosos que o familiar vá buscá-los, porém, essa busca é adiada diariamente e a esperança de voltar para casa é renovada pelos idosos, conforme identificado: "Eles sonham com o momento do familiar vir buscar. Mesmo que tu saiba que eles não virão. Tu precisa conversar, ter um jeito, dizer que amanhã eles vão, que o familiar irá buscá-lo". (C1, 32 anos).

E ainda: "agora, fim de ano, ele [idoso] tava bem deprimido, dai a gente tem que acalmar e dar atenção. Ele não fala mais, mas ele sente as coisas, às vezes tá olhando para a parede e escorre as lágrimas, é triste de ver". (C7, 46 anos). Esse abandono e carência por parte dos idosos contemplam a percepção dos cuidadores no que diz respeito ao envolvimento íntimo e afetivo, uma vez que, existe um envolvimento muito grande entre o cuidador e o idoso, ficando difícil separar o cuidado com a intimidade. Esses aspectos são vistos na última categoria contemplada desse estudo.

Assim, ao mencionar sobre o envolvimento íntimo que os cuidadores têm, observa-se que: " $a$ gente se envolve bastante, não tem como não sentir a dor deles, olhar um paciente sofrendo é difícil, já perdi paciente e isso causa um mal-estar, uma dor, é um ser humano que estava lutando e se foi". (C9, 39 anos). Nesse sentido, o cuidador age na esfera da intimidade do idoso, isto é, cria-se uma relação em que o idoso confia no profissional, deixando que ele tenha acesso a suas informações pessoais. Essa conclusão corrobora com os postulados de Zelizer (2011) sobre a economia do cuidado, mostrando que frequentemente as fronteiras entre dois mundos aparentemente separados e hostis entre si, geralmente são transgredidas.

As relações de intimidade com idosos vão depender do grau de confiança existente, sendo criada num continuum, dia após dia (ZELIZER, 2011). Essa construção da confiança é percebida quando os cuidadores mencionam que: "tem um paciente que eu cuido há um tempo que já somos amigos, faço a barba dele, ele 
só deixa eu fazer, corto o cabelo, ele me quer bem como um filho, estou com ele há um bom tempo, mais de um ano já". (C9, 39 anos). Assim, esse envolvimento emocional que existe entre os cuidadores e seus pacientes cria o estabelecimento de laços sociais profundos (PIRES; MAZON, 2017).

Também alguns cuidadores mencionam serem tratados pelos idosos ou por alguns familiares como membros da família, devido o apego e a confiança gerada no processo de cuidar. Outros têm somente ao cuidador, fazendo com que a relação se torne ainda mais fortalecida, pois: "alguns pacientes têm só os cuidadores na vida, que há anos não recebem uma visita. Mas, que bom que ainda tem alguém que se importa, alguém que cuida, alguém que zela". (C3, 30 anos). E, também, porque: "eles compartilham conosco momentos vivenciados, eles perguntam do nosso dia a dia fora do trabalho, a gente se sente integrante da familia deles sim". (C1, 32 anos).

Evidenciou-se que a intimidade entre cuidadores e idosos é um elemento constitutivo das relações de trabalho, e está associada ao conhecimento e informações compartilhadas, expressos pelo compartilhamento de segredos, informações corporais e memórias de situações difíceis vivenciadas anteriormente pelos idosos. Essas questões indicam condições de afeto e muitas vezes necessidade de suporte emocional.

[...] tive uma paciente que estava com câncer de pulmão, bem sofrida, do interior, e ela compartilhou comigo que tinha sido estuprada na infância. Ela pediu para eu não falar para ninguém, mas que ela precisava compartilhar e botar para fora. Existe muito isso de segredos, como eles nos falam, a gente tem que guardar para a gente. E por mais que as pessoas peçam (médicos, familiares) a gente não fala. É segredo! (C1, 32 anos).

E, ao mesmo tempo em que existem compartilhamentos de segredos, as cuidadoras mencionam que o recebimento de presentes como forma de agradecimento também é comum. Dizem que: "estamos sempre recebendo presentes, mimos. Já ganhei pão, cuca, bolinhos. E eles sentem a gente próximo, nos querem perto deles, é uma forma de agradecimento que eles têm conosco". (C1, 32 anos). Nesse sentido, faz-se uso da ideia de dinheiros especiais, onde atribui-se a incorporação social e simbólica ao significado dado ao dinheiro. Assim, cada tipo de dinheiro especial molda-se por diversas e diferentes redes de relações sociais e sistemas de significado (ZELIZER, 2010).

Encontram-se também as questões relacionadas ao luto, ao sofrimento que o cuidador também enfrenta quando perde seu paciente. Todos os entrevistados mencionam que existe uma angústia, uma dor profunda, devido os laços criados com o cuidador, pois: "nada supre a lacuna de quando um vem a falecer. É muito difícil. Essa barreira que você tem que passar, é complicado, no momento que você perde". (C1, 32 anos). No decorrer das entrevistas evidencia-se que os cuidadores descrevem variadas formas de sentir a morte do idoso, alguns relatam sentimento de impotência, insegurança, apego, tristeza e remorso.

\section{Considerações finais}

Objetivou-se, por meio desta pesquisa, investigar os reflexos que o trabalho de cuidador de idosos traz ao profissional que desempenha essa atividade, a partir da perspectiva da Economia do Care. Frente a isso, identificaram-se as principais percepções sobre a profissão de cuidador, a partir das experiências dos profissionais. Evidenciaram-se aspectos específicos que envolvem o trabalho do cuidador de idosos, atribuindo como fonte de renda a principal motivação. Assim como esses profissionais percebem a profissão com uma grande carga de sofrimento, tanto físico como psíquico, devido às demandas que o trabalho exige. Também foi observada a mercantilização do cuidado, quando se atribui ao dinheiro a capacidade de comprar o carinho, afeto e atenção que os idosos necessitam. E, por fim, observou-se que a intimidade e o envolvimento afetivo, criado nas relações diárias, faz com que as duas esferas (intimidade e economia) entrem em contato (ZELIZER, 2005), não conseguindo separar o mercado do cuidado profissional com os momentos íntimos que permeiam essa relação.

Este trabalho possibilitou conhecer mais acerca de uma profissão que possui baixa valorização social, mas de extrema importância para a sociedade. No entanto, observa-se que houve limitações que impediram trazer contribuições mais robustas, como o fato dos entrevistados, em alguns momentos, se emocionarem quando relatavam fatos de suas vivências, como sofrimento e histórias tristes dos idosos, o que deixava que a condução da entrevista ficasse em um único viés. Outra limitação do estudo é a necessidade de uma análise mais aprofundada da estrutura de trabalho dos cuidadores.

Estudos futuros poderiam aprofundar a análise a partir da psicodinâmica do trabalho, já comentada aqui, atentando para análises em torno da: a) organização do trabalho do cuidador a partir das suas características e rotinas; b) evidências da separação entre trabalho prescrito e trabalho real; e, c) vivências de prazer e sofri- 
mento. Estas categorias podem contribuir para trazer mais luz ao debate sobre as dimensões física e mental da saúde destes trabalhadores.

Pesquisas futuras ainda podem investigar outros grupos de cuidadores, como aqueles profissionais que realizam a atividade de cuidar como sua principal fonte de renda e as demandas específicas existentes em cada contexto de cuidado. Assim como percepções entre diferentes níveis de escolaridade e gênero, sendo que as pesquisas com cuidadores em sua maioria contemplam as mulheres. Identificar as demandas desses profissionais pode contribuir em uma redução do impacto negativo causado pela profissão, podendo-se realizar intervenções com maior eficiência, oferecendo melhores condições no ato de cuidar.

\section{Referências}

BANDELJ, N.; MORGAN, P.; SOWERS, E. Hostile Worlds or Connected Lives? Research on the Interplay between intimacy and economy. Sociology Compass, [s. l.], v. 9, n. 2, p. 115-127, Feb. 2015.

BARCA, M.; ENGEDAL, K.; LAKS, J.; SELBÆK, G. Quality of life among elderly patients with dementia in institutions. Dementia and Geriatric Cognitive Disorders, Basel, v. 31, n. 6, p. 435-442, Aug. 2011.

BARDIN, L. Análise de conteúdo. Lisboa, Portugal: 70, 2009.

BATISTA, A.; ARAÚJO, A. Intimidade e mercado: o cuidado de idosos em instituições de longa permanência. Sociedade e Estado, Brasília, v. 26, n. 1, p. 175-195, jan./abr. 2011.

BORGEAUD-GARCIANDÍA, N. Intimidad, sexualidad, demencias. Estrategias afectivas y apropiación del trabajo de cuidado en contextos desestabilizantes. Papeles del CEIC. International Journal on Collective Identity Research, Leioa, v. 2016, n. 1, p. 1-27, marzo 2016.

BRASIL. Câmara dos Deputados. Projeto de Lei PL $n^{\circ}$ 4.702, de 2012. Dispõe sobre o exercício da profissão de cuidador de pessoa idosa e dá outras providências. 12 nov. 2012. Disponível em: https://www.camara.leg.br/proposicoesWeb/ fichadetramitacao?idProposicao=559429. Acesso em: 10 mar. 2018.

BRASIL. Ministério da Saúde. Portaria n 1395, de 9 de dezembro de 1999. [Aprova a Política Nacional de Saúde do Idoso]. Diário Oficial: República Federativa do Brasil: seção 1, Brasília, DF, ano 137, n. 237-E, p. 20-24, 13 dez. 1999. Disponível em: http:// pesquisa.in.gov.br/imprensa/jsp/visualiza/index.jsp?jornal=1\&pagina=20\&data=13/12/1999. Acesso em: 20 mar. 2018.

BRASIL. Senado Federal. Projeto de Lei do Senado PLS n ${ }^{\circ} 284$, de 2011. Dispõe sobre o exercício da profissão de cuidador de idoso. Diário do Senado Federal, Brasília, DF, 26 maio 2011. Disponível em: https://legis.senado.leg.br/diarios/ BuscaDiario?codDiario=4076\&paginaDireta=18476\#diario. Acesso em: 10 mar. 2018.

CARRARO, P.; MAGALHÃES, C.; CARVALHO, P. Qualidade de vida de cuidadores de idosos com diagnóstico de Alzheimer e o emprego de acupuntura - Revisão de Literatura. Mudanças - Psicologia da Saúde, São Bernardo do Campo, v. 24, n. 2, p. 65-70, jul./ dez. 2016.

CRESWELL, J. Qualitative inquiry and research design: choosing among five approaches. 2nd ed. Thousand Oaks: Sage, 2007.

DA ROIT, B.; DE KLERK, J. Heaviness, intensity, and intimacy: Dutch elder care in the context of retrenchment of the welfare state. Medicine Anthropology Theory, Amsterdam, v. 1, n. 1, p. 1-12, 2014.

DENZIN, N.; LINCOLN, Y. Introduction: the discipline and practice of qualitative research. In: DENZIN, N.; LINCOLN, Y. (ed.). The SAGE handbook of qualitative research. $3 \mathrm{r}$ ed. Thousand Oaks: Sage, 2005. p. 1-32.

FALEIROS, A.; SANTOS, C.; MARTINS, C.; HOLANDA, R.; SOUZA, N.; ARAÚJO, C. Os desafios do cuidar: revisão bibliográfica, sobrecargas e satisfações do cuidador de idosos. Janus, Lorena, v. 12, n. 22, p. 59-68, jul./dez. 2015.

FIGUEIREDO, L. As diversas faces do cuidar: novos ensaios da psicanálise contemporânea. São Paulo: Escuta, 2009.

GUIMARÃES, N. Casa e mercado, amor e trabalho, natureza e profissão: controvérsias sobre o processo de mercantilização do trabalho de cuidado. Cadernos Pagu, Campinas, n. 46, p. 59-77, jan./abr. 2016.

HARTKE, R.; KING, R.; HEINEMANN, A.; SEMIK, P. Accidents in older caregivers of persons surviving stroke and their relation to caregiver stress. Rehabilitation Psychology, Washington, DC, v. 51, n. 2, p. 150-156, May 2006.

LIMA, S. O trabalho do cuidado: uma análise psicodinâmica. Revista Psicologia: Organizações e Trabalho, Florianópolis, v. 12, n. 2 , p. 203-216, maio/ago. 2012.

LOPES, R.; MITRE, N.; COELHO, M.; QUEIROZ, B. Perfil dos cuidadores das instituições de longa permanência para idosos de Itaúna - MG. ConScientiae Saúde, São Paulo, v. 11, n. 2, p. 338-344, abr.jun. 2012.

MARTINEZ, S.; BRÊTAS, A. O significado do cuidado para quem cuida do idoso em uma instituição asilar. Acta Paulista de Enfermagem, São Paulo, v. 17, n. 2, p. 181-188, abr./jun. 2004.

MOL, A. The logic of care: health and the problem of patient choice. London: Routledge, 2008.

PAULI, J.; GOERGEN, C.; GOLDONI, E. Intimidade negociada: a percepção dos cuidadores de idosos na perspectiva da economia do care. Desenvolvimento em Questão, Ijuí, v. 15, n. 39, p. 376-399, abr./jun. 2017.

PIRES, R.; MAZON, M. Trabalho e intimidade: a constituição profissional de cuidadoras em ambiente de home care. Tomo, São Cristóvão, n. 30, p. 337-357, jan./jun. 2017. 
ROCHA, M.; VIEIRA, M.; SENA, R. Desvelando o cotidiano dos cuidadores informais de idosos. Revista Brasileira de Enfermagem, Brasília, v. 61, n. 6, p. 801-808, nov./dez. 2008.

ROTE, S.; ANGEL, J.; MARKIDES, K. Health of elderly Mexican American adults and family caregiver distress. Research on Aging, Boston, v. 37, n. 3, p. 306-331, Apr. 2015.

SAIDEL, M.; CAMPOS, C. Family of older adults with mental disorder: perception of mental health professionals. Revista Brasileira de Enfermagem, Brasília, v. 70, n. 4, p. 753-760, jul./ago. 2017.

SCHORCH, M.; WAN, L.; RANDALL, D.; WULF, V. Designing for those who are overlooked: insider perspectives on care practices and cooperative work of elderly informal caregivers. In: ACM CONFERENCE ON COMPUTER-SUPPORTED COOPERATIVE WORK \& SOCIAL COMPUTING, 19., 2016, San Francisco. Proceedings [...]. New York: ACM, 2016. p. 787-799.

SILVA, I.; MACHADO, F.; FERREIRA, M.; RODRIGUES, M. Formação profissional de cuidador de idosos atuantes em instituições de longa permanência. Holos, Natal, ano 31, n. 8, p. 342-356, 2015.

SZNELWAR, L.; UCHIDA, S.; LANCMAN, S. A subjetividade no trabalho em questão. Tempo Social, São Paulo, v. 23, n. 1, p. 11-30, jan./mar. 2011.

THE CARE economy. International Labour Organization. [Genebra], c2018. Disponível em: http://www.ilo.org/global/topics/careeconomy/lang — en/index.htm. Acesso em: 19 abr. 2018.

TWIGG, J. Care work as a form of bodywork. Ageing \& Society, Cambridge, v. 20, n. 4, p. 389-411, July 2000.

ZELIZER, V. A economia do care. Civitas, Porto Alegre, v. 10, n. 3, p. 376-391, set./dez. 2010.

ZELIZER, V. A negociação da intimidade. Petrópolis: Vozes, 2011.

ZELIZER, V. The purchase of intimacy. Princeton: Princeton University Press, 2005.

\section{Priscila Cerutti}

priscilacerutti@yahoo.com.br

Mestrado em Administração pela Faculdade Meridional (IMED)

Professora na Faculdade Anhanguera

\section{Faculdade Anhanguera}

Rua Paissandú, 1200 - Centro

Passo Fundo - Rio Grande do Sul - Brasil

CEP: 99.010-101

\section{Jandir Pauli}

jandir.pauli@imed.edu.br

Doutorado em Sociologia pela Universidade Federal do Rio Grande do Sul (UFRGS)

Professor do Programa de Pós-Graduação Stricto Sensu em Administração na Faculdade Meridional (IMED)

\section{Vanessa Rissi}

vanessa.rissi@imed.edu.br

Doutorado em Psicologia pela Universidade do Vale do Rio dos Sinos (UNISINOS)

Professora do Programa de Pós-Graduação Stricto Sensu em Psicologia na Faculdade Meridional (IMED)

\section{Paula Gomes}

paulagomesrd@gmail.com

Especialista em Marketing pelo Centro Universitário Internacional (UNINTER)

Mestranda do Programa de Pós-Graduação Stricto Sensu em Administração da Faculdade Meridional (IMED)

\section{IMED}

Rua Senador Pinheiro, 304 - Vila Rodrigues

Passo Fundo - Rio Grande do Sul - Brasil

CEP: $99.070-220$ 


\section{Agência financiadora}

O presente trabalho foi realizado com apoio da Coordenação de Aperfeiçoamento de Pessoal de Nível Superior - Brasil (CAPES) - Código de Financiamento 001.

Processo: 1684675.

Período de execução: março de 2017 a dezembro de 2018.

\section{Contribuições dos autores}

A concepção do trabalho teve origem no grupo de pesquisa do projeto Organizações, Redes e Mercados e contestados e na disciplina de Sociologia Econômica, do curso de mestrado em Administração. Priscila realizou a análise e discussão dos resultados e auxiliou na construção do referencial teórico. Paula fez as entrevistas, transcrições e contribuiu na análise dos resultados. Jandir contribuiu na construção do referencial teórico sobre care economy, na análise e revisão. Vanessa contribuiu na discussão sobre relações de trabalho e revisão do artigo.
Aprovação por Comitê de Ética e consentimento para participação

Os entrevistados assinaram o Termo de Consentimento Livre e Esclarecido (TCLE) e a pesquisa seguiu as recomendações das Resoluções do Conselho Nacional de Saúde (CNS) 466/16, de 12 de dezembro de 2012 e CNS 510/16, de 07 de abril de 2016 e do Manual de Boas Práticas de Pesquisa da Associação Nacional de Pós-Graduação e Pesquisa em Administração (ANPAD).

\section{Consentimento para publicação}

Os sujeitos da pesquisa consentiram para a publicação dos resultados.

\section{Conflito de interesses}

Não há conflito de interesses. 